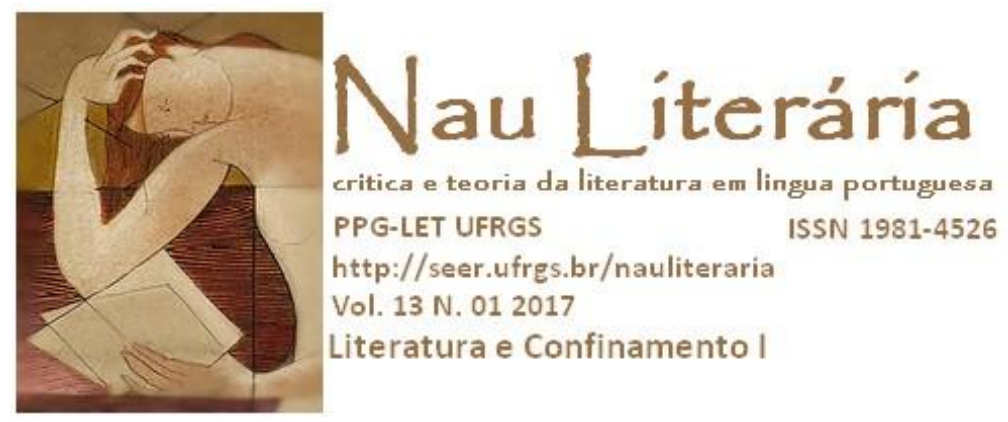

\title{
Literatura e reconstrução em contextos de pós-conflito: "estórias sem luz elétrica", de Ondjaki
}

Ana Margarida Ramos

Resumo: Pretende-se, neste estudo, proceder a uma leitura de duas narrativas de Ondjaki (Luanda, 1977), uma das mais originais e relevantes vozes da literatura angolana contemporânea, A bicicleta que tinha bigodes (Caminho, 2011) e Uma Escuridão Bonita (Caminho, 2013) à luz do contexto social, político e histórico que lhes serve de pano de fundo, a Angola do pós-independência. Os dois livros surgem unidos por um subtítulo comum, "estórias sem luz elétrica", o que lhes confere o estatuto de díptico, reforçado por outros elementos textuais e peritextuais, como a voz narrativa masculina e a sua associação à Avó Dezanove, no primeiro caso, e o formato da edição e autoria das ilustrações, no segundo, promovendo uma sugestão de continuidade que é mais implícita do que explícita.

Palavras-chave: Guerra; infância; reconstrução; literatura juvenil; Angola.

Abstract: The aim of this study is to analyse two short novels written by Ondjaki (Luanda, 1977), one of the most original and relevant literary voices in contemporary Angolan literature, namely A bicicleta que tinha bigodes (Caminho, 2011) and Uma Escuridão Bonita (Caminho, 2013). In these young adult novels, both set in the context of Angola post-independence, the social, political and historical backdrop is also part of the stories. The two books analysed are a diptych and they are united by a common subtitle, "stories without electricity", and also by other textual and peritextual elements such as the masculine narrative voice and the reference to "Grandma Nineteen", in the first case, and the book format and the illustrations, in the second, promoting a suggestion of continuity that that is more implcit than explicit.

Keywords: War; childhood; reconstruction; young adult literature; Angola.

\section{Introdução. Literatura para a infância no cenário de pós-conflito angolano}

A literatura para a infância angolana ainda possui um estatuto emergente, pese embora a crescente atenção internacional, do ponto de vista da edição, da crítica e da investigação académica, realizadas maioritariamente em Portugal e no Brasil (SECCO, 2007; DEBUS, 2013; GOMES, 2014). Os seus desenvolvimentos recentes, sobretudo neste milénio, em torno de figuras como José Eduardo Agualusa e Ondjaki, assentam num esforço iniciado ainda nas décadas de 70 e 80 do século XX, associado aos trabalhos de recolha e de edição do património literário oral, alvo de reescrita, adaptação e edição, muitas vezes realizada com apoio da imprensa - Jornal de Angola - e da Rádio Nacional de Angola. Aos textos 
tradicionais, de nítido recorte formativo e didático, juntam-se as reinterpretações da realidade, com o tratamento literário de questões como a guerra colonial e a revolução, mas também a criação de um universo de referências de cariz identitário, em torno de figuras históricas, da natureza e da cultura local:

\begin{abstract}
O colonialismo, as lutas pela Independência, os problemas internos oriundos das guerras civis provocaram sérias modificações na arte de narrar. Com a liberdade conquistada, tornou-se importante ensinar crianças e jovens a colocarem dentro de seus universos imaginativos o real das lutas guerrilheiras. [...] A euforia pós-independência, as críticas à colonização portuguesa são temas que aparecem recorrentemente nesta literatura infanto-juvenil, publicada em grande parte depois de 1975. Contudo, sem dúvida alguma, só a partir das décadas de 1980, 1990 e 2000, principalmente com a paz, é que uma nova literatura infanto-juvenil começou a surgir e ser editada em Angola e também Moçambique. (SECCO, 2007, p. 9-10)
\end{abstract}

De acordo com Simone Caputo Gomes (2014), esse tipo de evolução, comum aos vários países africanos de língua portuguesa, surge, em Angola, associado às figuras de Manuel Rui (Caixa), Maria Eugénia Neto (E nas florestas os bichos falaram) e Pepetela (As aventuras de Ngunga). Segundo a mesma autora (GOMES, 2014, p. 453), na década de oitenta, destaca-se a ação do Instituto Nacional do Livro e do Disco angolano, que permitiu a edição de várias histórias tradicionais para crianças, traduções de livros africanos na coleção "Menino Sol" e a estreia da coleção "Piô-Piô" (1982), na qual participaram autores como Darío de Melo, Octaviano Correia, Gabriela Antunes e Rosalina Pombal, por exemplo.

Luandino Vieira, pertencendo à mesma geração dos autores anteriormente referidos, só nos últimos anos começou a publicar de forma mais sistemática textos de destinatário infantil (ZUZA, 2014; RAMOS, 2016), unidos pela sua dimensão interventiva, com o tratamento de temas próximos dos da literatura para adultos. O escritor é também o responsável pelas ilustrações e grafismos que acompanham os seus textos, marcados pelas influências da oralidade e por uma escrita e registro pessoalíssimos, construídos na fusão do português com as línguas locais. Nessa medida, percorrem os vários volumes influências de tipo fabulístico e/ou lendário, inspirados na tradição oral, a brevidade, a comunicabilidade e a clareza das histórias narradas, cuja mensagem é passada de forma simples e acessível, mas sem concessões ou facilitismos, resultantes da consciência de que o texto-livro infantil é sobretudo uma história para ser contada em voz alta, assumindo o narrador a voz do contador. Mais recentemente, autores como José Eduardo Agualusa e Zetho Cunha Gonçalves também vieram enriquecer e diversificar o panorama literário infantojuvenil angolano com propostas originais que, sem deixar de lado as raízes orais e tradicionais, procedem à sua reinvenção num contexto globalizado, assumidamente contemporâneo e, até, pós-moderno. 
Ondjaki, como veremos, situa-se nessa corrente artística, unindo a tradição à modernidade, e procedendo à síntese de influências de um vasto conjunto de poéticas e de autores, nem todos com obra explicitamente destinada a crianças. A obra literária de Ondjaki corresponde já a um momento especial da evolução da literatura angolana, no qual são visíveis os ecos da realidade pós-independência, as consequências da guerra civil e o contexto de pós-conflito e de reconstrução, como já foi sublinhado por Devides (2014). As questões identitárias, centrais no universo pós-colonial, continuam a revelar-se estruturantes nos livros deste escritor, no seguimento das poéticas dos seus autores de referência, associadas à revalorização da cultura, da língua e de uma cosmovisão própria, no estabelecimento das fronteiras entre "nós" e os "outros" (AGNEW, 1998; MEEK, 2001; FOX, 2001; OMMUNDSEN, 2013).

À semelhança de outros países africanos com histórias tumultuosas de convulsão social e política no rescaldo de complexos processos de descolonização e de independência, “Children's literature represents an important resource for understanding the needs, wishes and aspirations of young people. African children's literature should be investigated more purposefully in order to address the misconception that children are some how yet to develop" (CHITANDO, 2008, p. 7). Para esta autora, que estudou o contexto do Zimbabué, a literatura infantil pode funcionar como "a valuable resource that illustrates the route to be followed in post-conflict transition. It interrogates the factors that threaten health and well-being, while describing the ideal society that overcomes conflict" (CHITANDO, 2008, p. 8), constatação que acreditamos estender-se à obra de Ondjaki na medida em que recria esse processo de transição, tendo como foco de interesse pessoal o universo infantil e adolescente e o microcosmo de Luanda. A investigadora identifica quatro principais problemas ligados às crises/conflitos vividos na História contemporânea do Zimbabué, decorrentes da luta pela independência, ocorrida apenas em 1980, associados à violência enraizada na identidade do país, à tensão racial e à divervsidade étnica, à pobreza e à desigualdade na distribuição dos recursos, e às desigualdades entre os géneros, cujos reflexos se estendem à literatura infantil daquele país, em franco crescimento e afirmação.

À recriação literária de temas controversos - aspecto marcante das sociedades de pósconflito - como a guerra, os conflitos raciais, a pobreza, a discriminação de género, o HIV e a SIDA, a intolerância assume uma clara funcionalidade de denúncia, exprimindo desejos de um mundo mais pacífico, muitas vezes em textos assumidamente idealistas e utópicos, mas também apontando caminhos de reconstrução e reconciliação social e de fomento da integração da diversidade e das diferenças. Essa reflexão, salvaguardadas as devidas 
diferenças, é extensível ao contexto angolano, cuja produção literária infantil se debate com questões semelhantes, exprimindo não só as especificidades das vivências angolanas, mas cristalizando uma certa imagem universal da infância, caracterizada pela esperança inabalável na felicidade.

Pretende-se, aqui, analisar a forma como são literariamente recriados, em duas narrativas juvenis de Ondjaki, os ecos da guerra civil e as suas consequências nas vivências quotidianas, a instabilidade e a incerteza do contexto pós-conflito, a pobreza e a desigual distribuição da riqueza, a esperança e o sonho que se cruzam nas narrativas com a experiência da infância, uma espécie de filtro ingénuo e inocente através do qual é percecionada a realidade. Centradas no universo infantil, no olhar e nas vozes das crianças, as narrativas convidam à revisitação de um espaço específico, uma Luanda caleidoscópica, movediça e vibrante.

\section{Os conflitos bélicos nas obras para crianças e jovens de Ondjaki}

Artista multifacetado, Ondjaki (Luanda, 1977), nome literário de Ndalu de Almeida, tem-se dedicado preferencialmente à escrita literária (para crianças, jovens e adultos), para além da pintura e da representação, em teatro, mas também à escrita para cinema. $\mathrm{O}$ escritor, com formação em Sociologia e em Cinema, foi já distinguido internacionalmente com numerosos prémios ${ }^{1}$, incluindo o prestigiante Prémio José Saramago, em 2013, para o romance $O s$ Transparentes ${ }^{2}$. A temática da guerra, vivida ou lembrada, está presente na sua produção literária, tanto para crianças como para adultos, em estreita ligação com as vivências diretas e indiretas do autor, nascido durante a guerra civil angolana e conhecedor das suas consequências. A seleção de contextos africanos, tanto em termos de espaço como de tempo, o tratamento de temáticas de índole identitária e o recurso a um registro e uma linguagem muito próprios são elementos recorrentes na sua produção literária, ilustrando, simultaneamente, o cariz pós-colonial das suas propostas.

O tema da guerra é central no livro Ynari. A menina das cinco tranças (2004), cuja localização espacial se situa no continente africano. A narrativa trata a questão da pacificação de conflitos e do fim da violência, procedendo a um elogio da paz e da participação ativa da

\footnotetext{
${ }^{1}$ Entre os mais relevantes, destacam-se o Grande Prémio APE (Portugal, 2007) para a obra Os da minha rua; o Grinzane for Africa Prize - Young Writer (Etiópia/Italia/2008); o Prémio FNLIJ 2010 "Literatura em Língua Portuguesa", para AvóDezanove e o segredo do soviético (Brasil), que também foi distinguida como o Prémio Jabuti, categoria juvenil, em 2010. Ondjaki recebeu ainda o Prémio Caxinde do Conto Infantil, com Ombela, a estória das chuvas (Angola, 2011).

2 Também distinguido em França, com o Prix Littérature-Monde 2016.
} 
criança na sua construção. O relevo das palavras no processo de união dos povos desavindos simboliza o poder do diálogo e do próprio discurso na solução de conflitos. A redação do texto, datada de 2002, não será alheia ao ano do final do conflito bélico interno em Angola, exprimindo um desejo latente - mesmo se utópico - de paz e de reconciliação. A influência da literatura tradicional, em particular do universo dos contos maravilhosos, está patente na estrutura da narrativa, bem como na abertura e no fecho, para além do registro, assumidamente oralizante, próximo do contador de histórias.

Os conflitos voltam a surgir, com ligeiros cambiantes, em $O$ Leão e o Coelho Saltitão (2008), uma recriação do relato de David Yava Mwau, intitulado "Ciximo Ca Ndumba Na Mbwanda" (Estória do Coelho e do Leão) ${ }^{3}$, um texto que apresenta marcas da fábula e retoma elementos-chave das histórias tradicionais africanas, nomeadamente através da recuperação do confronto entre o leão e o coelho, simbolizando, respectivamente, a força e a esperteza. A vitória sucessiva do segundo sobre o primeiro institui uma espécie de justiça universal, uma vez que dá esperança aos mais fracos e aos mais pequenos. O texto distingue-se pela inclusão de segmentos poéticos, cantados, reforçando a dimensão oral de um texto no qual os diálogos são frequentes e abundantes, e cujas personagens surgem tipificadas e agem de acordo com os arquétipos narrativos ancestrais, encarnando simbologias e motivações particulares.

Os conflitos bélicos voltam a marcar presença em outros volumes ${ }^{4}$, menos explicitamente dirigidos ao universo infantil, como Bom Dia Camaradas (2003), Os da Minha Rua (2007), AvóDezanove e o Segredo do Soviético (2008), por exemplo, sem a centralidade narrativa que conhecem nos textos analisados anteriormente, pelo que, pelas limitações deste estudo, cingimos a análise a apenas duas narrativas ${ }^{5}$ breves, $A$ bicicleta que tinha bigodes (2011) e Uma escuridão bonita (2013). As relações existentes entre estes volumes, ambientados no mesmo contexto, são, contudo, evidentes, sublinhadas até pelas

\footnotetext{
${ }^{3}$ Publicado no livro Viximo, contos da oratura Luvale, de José Samuila Cacueji, União dos Escritores Angolanos, 1987.

${ }^{4}$ As obras aqui elencadas têm várias afinidades com o corpus selecionado para este estudo, tendo em conta o ponto de vista narrativo e o contexto social e espacial da ação, situado na cidade de Luanda, da década de 80 e 90, e que recriam as consequências diretas e indiretas da guerra civil e dos problemas políticos e sociais que o país enfrentava. A leitura desses textos à luz das suas afinidades biográficas com a infância e a adolescência do autor pode ser um ponto de partida relevante, aliás, já parcialmente levado a cabo por Faria (2012), quando estuda as representações da infância em quatro obras de Ondjaki. Nessa medida, várias das conclusões e das análises aqui sugeridas são facilmente aplicáveis a esse conjunto de obras, também situadas em contexto de conflito e pós-conflito, onde surgem vários ecos das convulsões que o país atravessa, filtradas pelo imaginário infantil que os integra e normaliza no seu quotidiano.

5 Ambos os livros aqui analisados foram distinguidos com o Prémio FNLIJ "Literatura em Língua Portuguesa", em 2013 e 2014, respetivamente.
} 
alusões intertextuais ${ }^{6}$ de tipo homoautoral, numa estratégia de autorreferencialidade que faz desses livros uma espécie de macrotexto singular.

\subsection{Análise do díptico "estórias sem luz elétrica"7}

O díptico formado pelas novelas A bicicleta que tinha bigodes (2011) e Uma escuridão bonita (2013), ambas publicadas com o subtítulo "estórias sem luz elétrica", é, a propósito do tema que aqui nos ocupa, paradigmático, na medida em que a guerra já não é o cerne das narrativas, mas ecoa, ao longe, no espaço ou no tempo, sendo indiretamente refletida nas vivências das personagens centrais. Para além do subtítulo comum, “estórias sem luz elétrica", outros elementos textuais e peritextuais reforçam a unidade das novelas, como a voz narrativa masculina e a sua associação à Avó Dezanove, no primeiro caso, e o formato da edição e autoria das ilustrações, no segundo, promovendo uma sugestão de continuidade implícita entre os dois volumes. A figura da AvóDezanove é outro elemento que une as narrativas, assinalando o seu lugar tutelar no bairro e no crescimento do narrador. Personificando a resistência, a coragem, mas também o altruísmo e a esperança, a Avó é uma espécie de porto seguro que mantém o narrador firme e estável, mesmo nos momentos mais difíceis.

\subsection{A bicicleta que tinha bigodes}

Na primeira narrativa, Prémio Bissaya Barreto em 2012, a guerra aludida, mais ou menos presente, é uma espécie de referência a que todos já se habituaram, uma entidade anónima e autónoma, que parece agir por conta própria, sem intervenção humana. O texto recupera o imaginário infantil de Luanda, retomando personagens e universos recorrentes na ficção do autor. O texto, apesar de assumidamente realista, é intersecionado por uma

\footnotetext{
${ }^{6}$ A AvóDezanove é personagem de vários volumes; a bicicleta com bigodes montada pelo Tio Rui tinha aparecido num sonho em Avó Dezanove e o segredo do soviético, sendo central na novela com título homónimo; o cinema ao ar livre surge em Os da minha rua e em Uma escuridão bonita; para além de um sem número de referências comuns, como as telenovelas brasileiras, as brincadeiras na rua, algumas perigosas e arriscadas, os cortes de luz e água, as amizades entre as crianças, as alusões políticas de vária ordem, aos militares, aos estrangeiros, nomeadamente soviéticos, a vivência dos primeiros amores da adolescência, o relevo das varandas e de outros espaços simbólicos, como o quintal, quase todos ao ar livre ou de transição entre a casa e a rua, a interseção do fantástico e do inexplicável, na esteira do realismo mágico, a comunidade envolvente, feita de familiares e vizinhos que se conhecem e se visitam, só para dar alguns exemplos.

${ }^{7} \mathrm{Em}$ 2017, o autor publicou mais um volume cujo subtítulo também é "estórias sem luz elétrica", intitulado $O$ convidador de pirilampos (Editorial Caminho). Este livro, apesar de conter ilustrações e design gráfico de António Jorge Gonçalves, distingue-se dos anteriores por elementos peritextuais (como o formato e a capa dura) e textuais, como a voz narrativa ou o tema, razão pela qual não foi incluído neste estudo.
} 
dimensão onírica e maravilhosa associada aos sonhos do protagonista, mas também aos poderes mágicos dos bigodes do Tio Rui que, uma vez penteados e cortados, revelam esconder restos de letras, prontos a formar palavras, génese da criação literária.

A narrativa caracteriza-se por uma forte dimensão metaficcional, associada à redação da história para o concurso como motor de grande parte da intriga, a que se soma a reflexão sobre a escrita e o processo criativo, e a inclusão, como paratexto final, da carta do narrador ao Presidente de Angola, solicitando um brinquedo para cada criança do país. A presença de uma personagem referencial, identificável com o escritor-poeta Manuel Rui, também duplica os diferentes níveis de leitura da novela, dado que colabora na reflexão de tipo metaliterário, além de revelar o seu processo criativo, desvendando os segredos e mistérios da ficção. É, igualmente, a figura de referência da narrativa, uma espécie de mediador de conflitos, sábio, ponderado, justo, imparcial e conselheiro, a quem as crianças recorrem com frequência. A disponibilidade com que as recebe e a atenção que lhes dedica solidificam o seu estatuto e importância no bairro, mas também na própria história, que lhe é "dedicada", a fazer fé nos paratextos introdutórios do livro.

A linguagem da narrativa é muito apelativa em resultado da combinação de diferentes registros, permitindo acompanhar a evolução das várias emoções das personagens e promovendo a empatia dos leitores com as situações vividas. O texto não passa ao lado de uma forte dimensão crítica, característica da obra do escritor, sobretudo em termos políticos e sociais, não só pondo a nu as desigualdades existentes, mas perspectivando-as a partir das franjas populares e periféricas da sociedade, os cidadãos anónimos. O olhar infantil, inocente e ingénuo, afastado do poder, é o que melhor serve para pôr a nu as contradições e os equívocos da governação, mas também ilustrar as consequências humanas e pessoais das decisões junto das vítimas inocentes dos desmandos do poder.

A centralidade do universo infantil, a partir do qual é perspetivado o real, não apaga as especificidades de cada uma das personagens, com personalidades próprias e distintas. $\mathrm{O}$ narrador, Isaura e JorgeTemCalma ilustram a diversidade da vivência infantil, mas também a força da amizade, capaz de superar diferenças. É também nesse universo infantil que repercutem com mais intensidade os ecos dos conflitos, mesmo se distantes. A banalização dos cortes de luz e água, tão frequentes que se transformam em rituais pelos quais as personagens balizam os dias e organizam o quotidiano, é, possivelmente, o impacto mais visível da guerra. A Edel, Empresa de Distribuição de Eletricidade, é recriada como uma 
entidade que decide, de forma aleatória ${ }^{8}$, sobre os cortes de luz, em alguns casos, fazendo a vontade às crianças que preferem a escuridão ${ }^{9}$ da noite para viverem mais intensamente as suas aventuras:

\begin{abstract}
A Edel foi nossa amiga e a luz foi. Quando a luz vai, as conversas de rua ficam mais mágicas: os olhos tipo que brilham de outra maneira, as pessoas saem à rua e ficam a imaginar o que poderia estar a acontecer na telenovela, todos querem saber se no dia seguinte a TPA vai repetir o capítulo que todo o mundo não viu, a minha Avó fica no muro a rir das nossas histórias ou conta também uma estória de antigamente, o CamaradaMudo não entra para jantar, a noite fica mais quente, os carros passam devagar porque as crianças brincam no meio da rua, alguém liga um rádio barulhento que quase não se ouve por causa do barulho do gerador do GeneralDorminhoco, um cheiro de petromaxes fica a passear pelos nossos narizes, dá para roubar mangas, goiabas e pitangas nas árvores alheias e se jogamos escondidas aqueles que não são da nossa rua demoram muito tempo para nos encontrar porque não conhecem os lugares melhores com bons esconderijos, tipo o vóx-váguen da doutora Victória, ou um galinheiro abandonado, ou mesmo a casa aberta de qualquer vizinho onde só nós, os da rua, podem entrar sem pedir com-licença, quando a luz vai na minha rua, as crianças afinal reclamam de não ver novela mas no fundo no fundo, ficamos contentes porque podemos fazer mil coisas fora do ritmo normal das nossas vidas. (ONDJAKI, 2011, p. 52-53)
\end{abstract}

A Rádio e a Televisão surgem como as fontes de informação oficiais, sobretudo a primeira, a que se juntam os boatos e as vozes populares, ampliando (às vezes distorcendo) as notícias. A guerra também chega a Luanda através dos meios de comunicação, surgindo banalizada e perfeitamente incorporada na rotina dos dias, uma vez que é assumida como propriedade do país: "Era hora do noticiário e explicaram coisas da nossa guerra, falaram também da falta de água e de uma falta de luz que também poderia acontecer devido aos combates perto de Cambambe" (ONDJAKI, 2011, p. 45);

Depois vieram as notícias da guerra, depois makas das fábricas que andavam a não funcionar. Ainda o locutor falou da falta de luz que ainda não tinham encontrado uma explicação muito boa, falaram do tal Á-Éne-Cê da África do Sul e do coitado do camarada Mandela que continuava preso. (ONDJAKI, 2011, p. 78)

A política internacional e a clivagem ideológica entre as potências mundiais é também explicitada, surgindo não só do ponto de vista do discurso oficial, já absorvido pela

\footnotetext{
${ }^{8}$ Confirmar com o seguinte excerto: “ - Camarada Mudo - a Isaura começou -, assim foi avaria só de quinze minutos ou é coisa séria?

- Pelo modo como a luz foi, assim sem tremer nem nada, acho que foi mesmo corte intencional.

- 'Corte intencional' é como então? - eu perguntei.

- É quando a Edel corta a luz porque quer.

- Mas a Edel existe para dar ou para cortar a luz?” (ONDJAKI, 2011, p. 19-20).

${ }^{9}$ Ver o seguinte exemplo: "A noite na nossa rua ficou bonita. Como não havia luz, alguns trouxeram pequenas lanternas de luz fraquinha, outros umas velas bem cambutas, um petromax também de se poupar e até dois candeeiros daqueles com garrafa de vidro e depósito para o azeite" (ONDJAKI, 2011, p. 30).
} 
população e pelas crianças, mas também na recusa do Tio Rui em ouvir a Voz da América, dando conta da ideologia dominante, de que o final da narrativa é particularmente elucidativo:

- Tio Rui, as estrelas têm dono?

- Têm, sim.

- São de quem?

- São do povo. (ONDJAKI, 2011, p.86)

As faltas de água, por seu turno, surgem associadas à figura da AvóDezanove que rega todos os dias o quintal, quer haja água, quer não, mantendo-se fiel ao seu ritual de cuidar das plantas, como se a intenção também as alimentasse e mantivesse vivas e frescas:

Um dia alguém disse que aquela era uma luz muito fresca, eu ria de ouvir essas frases dos poetas, "luz fresca", como a água da Avó regar as plantas verdes de manhã, isso quando a água vinha. Se a água não viesse, a minha Avó, que é muito engraçada, regava mesmo assim.

- Só de mangueira a fingir numa água que ainda lá está na barragem, Avó?

- Assim mesmo.

- Tipo que és do teatro dos jardineiros?

- Tipo - a Avó sorria, os gestos dela continuavam a abanar a mangueira sem água nenhuma, só umas gotas sacudidas do dia anterior ou quê.

- Assim estás a regar como, Avó?

- A regar só. As plantas sabem.

A regar só. A avó ficava bué de tempo a "regar só". Mesmo deixava passar esse tempo como se fosse uma demora de molhar. E olhava o céu num pedido de pingos.

- Pediste água dos céus, Avó, no tal camarada que abre torneiras?

- Pedi.

- Hum, melhor é só pedir água à Epal, pode ser que te aceitem na conta de seres mais-velha respeitada. (ONDJAKI, 2011, p. 41-42)

Outras consequências visíveis, sentidas no dia a dia, são a falta de alimentos e outros bens essenciais, para o cidadão comum, uma vez que estes parecem estar disponíveis, no mercado negro $^{10}$, para alguns. A desigualdade na distribuição dos alimentos torna-os raros e valoriza a sua importância, sobretudo aos olhos das crianças. Em casa do Tio Rui, por exemplo, as três crianças que protagonizam a narrativa podem beber sumo tang, mais ou menos aguado, comer pão com queijo ou gelado, verdadeiros luxos numa Luanda a braços com problemas de abastecimento de água e eletricidade. Os pequenos prazeres da abundância, raros e preciosos, são saboreados como dádivas, fazendo esquecer depressa a desilusão pela perda do concurso de estórias da Rádio Nacional, mas sublinhando novamente o fato de as carências não serem sentidas por todos da mesma forma:

Além do sumo tang de maracujá, a tia Alice tinha preparado uma coisa espantosa: sanduíche de pão com manteiga só que lá dentro tinha mesmo posto um pedaço grosso daquele queijo de capa encarnada.

\footnotetext{
${ }^{10}$ Ver o exemplo seguinte: "Barulhos vieram da rua. O jipe do GeneralDorminhoco saiu, devia ir buscar pão numa loja que sempre tinha pão para o camarada GeneralDorminhoco" (ONDJAKI, 2011, p. 43).
} 


\begin{abstract}
- E hoje o sumo não é aguado - o tio Rui avisou.
Era verdade, o sumo tava bem doce que até ficava muito tempo na boca o sabor daquele açúcar assim castanho que usavam na casa do tio Rui. (...) Voltou com um gelado e enorme, daqueles de balde que não víamos há muito tempo. Devem ter conseguido tanto gelado na casa de um camarada importante com um gerador que até aguenta arcas e geleiras (ONDJAKI, 2011, p. 79-81).
\end{abstract}

Em casa, são perceptíveis, mesmo para o olhar mais inocente do neto, os estratagemas da avó para multiplicar os alimentos, de modo que as crianças continuem a ser alimentadas, mesmo à custa do sacrifício pessoal:

O matabicho ia aparecendo, devagar, para parecer que tinha muita coisa. A minha Avó com os teatros dela: bocados de pão, depois a manteiga, leite aguado já misturado assim na cozinha para eu não ver, um bocadinho de café que eu sempre pedia.

- Avó, tu não tomas leite?

- Só café.

Era mentira de poupar as coisas para as crianças, pois quando havia mais de um pacote a Avó também matabichava leite. (ONDJAKI, 2011, p. 42).

Os dirigentes políticos, angolanos e internacionais, são alvo da ironia fina, presente desde logo nos nomes não inocentes dos animais batizados por Isaura, mas também nas alusões aos camaradas mais-velhos, com responsabilidades na organização do país. A carta final do narrador ao camarada presidente é uma espécie de manual de boa governação, deixando implicitamente perceber as falhas cometidas, sobretudo em termos de distribuição da riqueza e de organização. Aliás, a crítica é explicitada na narrativa, quando o narrador confidencia à Avó que “o camarada presidente devia organizar melhor o nosso país. [...] Devia dar bicicletas sem ser preciso uma pessoa estar a inventar estórias. Ainda pode acontecer que as crianças fiquem mentirosas" (ONDJAKI, 2011, p. 42).

O duplo sentido dos nomes dos animais é explorado ao longo de toda a narrativa, criando cenas particularmente sugestivas, como quando Isaura teme que o gato francês tenha comido o gafanhoto Mobutu, ou quando o gato, depois de castrado, muda de nome, deixando de ser Tátecher e passando a ser Ghandi, tornando-se pacífico e deixando de atacar os papagaios.

\title{
2.3 Uma escuridão bonita
}

O segundo texto aqui em análise consiste, em linhas muito gerais, numa narrativa protagonizada por dois adolescentes que, numa noite em que falta a luz em Luanda, ensaiam o seu primeiro beijo. Mais uma vez, a falta de luz volta a ser o pretexto para o desenvolvimento 
da intriga, aproximando as personagens que, escudadas pela escuridão, abrem-se à partilha de confidências e intimidades que a luminosidade não permite. A escuridão também parece desenvolver outras formas de apropriação do mundo, de olhar com outros sentidos o que se passa à sua volta. Dessa forma, o registro sensorial ganha particular relevo, com o desenvolvimento de uma sensibilidade peculiar do narrador que, às escuras, está atento aos cheiros, aos sons e aos silêncios, ao tato, aos movimentos e às sensações térmicas que o rodeiam. A sensibilidade aumenta à medida que a aproximação entre o par ocorre, num crescendo lento e gradual de emoções que o discurso exprime de forma emocionada.

O diálogo mantido entre os dois protagonista na varanda, que culminará num beijo, é pontuado pelas aparições da AvóDezanove ${ }^{11}$ na varanda, perguntando, sem esperar resposta, “Tudo bem aqui na varanda?”. Quase como um refrão que ecoa na noite e reverbera no imaginário recriado, iluminado pela luz da vela, a pergunta da Avó traz os adolescentes momentaneamente de regresso ao espaço da varanda.

O texto distingue-se do anterior por agora ser dada voz a uma perspectiva adolescente, caracterizada pela originalidade do seu olhar sobre o mundo, as pessoas, os afetos e as relações. O poder da voz narrativa seduz o leitor e mantém-no preso ao fio de uma história cujo enredo avança muito lentamente, em resultado de um discurso que, sendo acessível, não deixa também de ser sensível e profundamente poético. Este livro, selecionado para lista White Ravens em 2014, foi também objeto de distinção pelo Prémio Nacional de Ilustração, atribuído a António Jorge Gonçalves. O peculiar design gráfico do livro explora os efeitos do jogo entre o branco da mancha gráfica e o preto do fundo das páginas, materializando no livro o contexto de falta de luz que serve de pano de fundo à história. Esta, muito mais intimista do que a anterior, situada numa única noite, na varanda da casa do narrador, é menos permeável aos ecos do contexto social e político que funciona como cenário.

Ainda assim, ficamos a saber que o pai da adolescente por quem o narrador está enamorado morreu na guerra, o que a transforma em órfã do conflito militar que, durante décadas, persistiu em Angola. Assim, não surpreende que "o desejo de estrelas" da personagem seja verbalizado da seguinte forma: "Desejo que o meu pai não tivesse morrido na guerra" (ONDJAKI, 2013, p. 22), imediatamente corroborado pelo narrador quando afirma "E eu desejo que os homens nunca mais inventem guerras novas" (idem), o que aponta para a localização da narrativa num momento temporal posterior a 2002, fim do conflito militar em

\footnotetext{
${ }^{11}$ A AvóDezanove é ainda a protagonista de uma narrativa encaixada na principal sobre a explicação do acontecimento que deu origem ao seu nome e que envolve um soviético que se teria apaixonado por ela, numa alusão intertextual a um outro romance do autor intitulado AvóDezanove e o segredo do soviético (2008).
} 
Angola. A maior extensão do desejo, abrangendo outros contextos, é expressa metaforicamente, associado ao esvaziamento do "saco das guerras" (idem) ou mesmo à possibilidade de que os homens "tivessem perdido o caso das guerras" (idem). O desejo de uma ponte - um arco-íris - que ligasse este mundo ao outro e que permitisse chamar "quem tivesse partido ainda em hora de cá estar” (ONDJAKI, 2013, p.4 2), permitindo o regresso do pai e "também as crianças de todas as guerras" (idem), é sintomático deste sentimento de perda e de ausência profundamente enraizado que resulta dos traumas vividos nas sociedades pós-conflito, conduzindo frequentemente à verbalização do desejo de paz universal, mesmo se utópica, e surgindo expressa em várias manifestações artísticas.

$\mathrm{O}$ momento alto da narrativa, associado à partilha do Cinema $\mathrm{Bu}$, "veloz e pobre" (ONDJAKI, 2013, p. 84), mas mágico, talvez por ter de "ser vivido num tempo mais curto que a chama de um fósforo" (idem), também resulta do contexto partilhado pelas crianças da rua, que aguardam, na escuridão da noite, a passagem de um carro para momentaneamente iluminar a parede onde são projetadas as sombras em movimento de objetos e seres. Este divertimento pobre, vivido intensamente pelos miúdos, ilustra não só a criatividade das crianças, habituadas a tirarem partido das situações mais banais, mas também a pobreza e a privação de formas de diversão, limitadas a verem a noite iluminada e projetada pelos faróis dos carros que passam na estrada. O livro explora graficamente essa sugestão de imagens em movimento, através da inclusão de uma dupla página dobrada, que uma vez desdobrada duplica o espaço disponível para as ilustrações, simulando a projeção do cinema $\mathrm{Bu}$ e explorando os efeitos de luz e sombra e de movimento que lhe estão associados. O sucesso do cinema depende, em boa verdade, da capacidade de imaginação dos espectadores, verdadeiros cocriadores da magia, na medida em que "a coisa mais bonita do Cinema Bu é que cada um pode encontrar ali as memórias, os sonhos, e os futuros que mais deseja" (ONDJAKI, 2013, p. 82), funcionando, afinal, como forma extrema de liberdade, mesmo se efémera e fugidia, uma centelha de esperança que ilumina as noites e os sonhos das personagens. As histórias que o narrador inventa e com as quais delicia e seduz a sua companheira ilustram também a sua imaginação criativa, forma suprema de embelezar a escuridão, literal e simbólica, que o rodeia.

\section{Considerações finais}

As duas narrativas analisadas surgem unidas pelas referências aos cortes de luz constantes, às quebras no abastecimento de água, à irregular distribuição dos bens de 
consumo, às desigualdades sociais e à improvável capacidade de superar todas as limitações, uma espécie de dádiva de esperança aos leitores que transforma os textos não só numa ferramenta de denúncia, mas também num manifesto redentor, em linha com a tendência mais interventiva da literatura contemporânea. Ambas as narrativas dão conta, de forma indireta, sob a forma de referências ou alusões, das consequências da guerra civil angolana, mesmo se distante, no espaço e no tempo, na vida e no quotidiano das personagens. A perda de familiares, o sentimento de orfandade latente, a falta ou a limitação de bens essenciais, como a eletricidade, a água ou a alimentação, e a desigualdade na distribuição da riqueza existente surgem como pano de fundo para narrativas que se centram sobretudo em dilemas existenciais do quotidiano infantil e adolescente dos habitantes de Luanda.

A eternização dos combates parece banalizar as suas consequências que rapidamente são interiorizadas pelas personagens, habituadas à única realidade que conhecem. Ainda que a denúncia da responsabilidade política e moral desses conflitos seja feita, a verdade é que as rotinas das crianças continuam a ser marcadas pelas brincadeiras, os jogos, as amizades e os afetos. Essa é, possivelmente, a crítica implícita mais forte que decorre da leitura dos textos à luz desta perspetiva: a de que os crimes cometidos contra a inocência e o futuro das crianças não são menos graves pelo facto de elas, contra todas as expectativas, viverem ainda felizes e despreocupadas.

A falta de luz que une os dois livros - e as vidas dos habitantes do bairro - funciona narrativamente como o gatilho que dá origem às histórias, uma espécie de ponto de partida para a fantasia e a imaginação, dado que a escuridão, mais ou menos bonita, parece ser ingrediente fundamental das aventuras das personagens. É visível, entre os dois volumes, a passagem do tempo, não só porque a guerra terminou, mas porque o narrador passa da infância para a adolescência descobrindo novos interesses. O registro também amadurece e, em sintonia com o tema tratado, torna-se, no segundo livro, mais poético e intimista. $\mathrm{O}$ lirismo que percorre todo o texto e o enche de imagens, metáforas, comparações, resulta do diálogo entre os protagonistas e das tentativas mútuas de aproximação.

A interseção de uma dimensão utópica, em linha com as tendências da literatura infantil produzida em contextos de pós-conflito (CHITANDO, 2008), sugere também uma leitura atemporal das obras, não restrita ao contexto de escrita ou das narrações, mas igualmente suscetível de promover esse diálogo.

\section{Referências}


AGNEW, John. Introduction: European Landscape and Identity. In: GRAHAM, Brian (Ed.). Modern europe: place, ulture and identity. London: Arnold, 1998, p. 213-235.

CHITANDO, Anna. Imagining a peaceful society: a vision of children's literature in a postconflict Zimbabwe. Uppsala: Nordiska Afrikainstitutet, 2008. Disponível em <http://www.diva-portal.org/smash/get/diva2:241306/FULLTEXT01.pdf〉. Acesso em: 4 jun. 2016.

DEBUS, Eliane. A literatura angolana para a infância. Educação \& Realidade, v. 38, n 4, 2013. p. 1129-1145. Disponível em <http://www.scielo.br/pdf/edreal/v38n4/07.pdf>. Acesso em: 4 jun. 2016.

DEVIDES, Michele M. Evidências de discurso de resistência na iteratura infantil de Ondjaki: uma análise da obra Ynari, A Menina De Cinco Tranças. Rehutec, vol. 4, nº 1, 2014. p. 289303. Disponível em <http://www.divaportal.org/smash/get/diva2:241306/FULLTEXT01.pdf>. Acesso em: 4 jun. 2016.

FARIA, Helena Maria Martins. As crianças na narrativa de Ondjaki. 2012. Dissertação (Mestrado em Estudos Românicos) - Faculdade de Letras da Universidade de Lisboa, Lisboa, 2012. Disponível em <http://repositorio.ul.pt/bitstream/10451/9930/1/ulfl141494_tm.pdf >. Acesso em: 4 jun. 2016.

FOX, Carol. Conflicting Fictions: national identity in English children's literature about war. In: MEEK, M. (Ed.). National identity and children's literature. London: Trentham Books, 2001. p. 43-58.

GOMES, Simone Caputo. Algumas linhas para abordagem da literatura infantil e juvenil na África de língua portuguesa. In: COELHO, Nelly Novais; CUNHA, Maria Zilda da; BASEIO, Maria Auxiliadora Fontana (Ed.). Tecendo literatura: entre vozes e olhares. São Paulo: Humanitas, 2014. p. 451-467.

MEEK, Margaret. (Ed.). National identity and children's literature. London: Trentham Books, 2001.

OMMUNDSEN, Ase Marie (Ed.). Looking out and looking in. National identity in picturebooks of the new millenium. Oslo: Novus AS, 2013.

ONDJAKI. A bicicleta que tinha bigodes. Estórias sem luz elétrica. Ilustrações de António Jorge Gonçalves. Alfragide: Caminho, 2011.

Uma escuridão bonita. Estórias sem luz elétrica. Ilustrações de António Jorge Gonçalves. Alfragide: Caminho, 2013.

RAMOS, Ana Margarida. Fábulas e parábolas: aproximações aos livros para crianças de Luandino Vieira. In: TOPA, Francisco; PEREIRA, Elsa (Ed.). De Luanda a Luandino: veredas. Porto: CITCEM/Afrontamento, 2016. p. 183-189.

SECCO, Carmen Lúcia Tindó (Org.). Ensaios sobre literatura infantil de Angola e Moçambique: entre fábulas e alegorias. Rio de Janeiro: Quartet, 2007. 
ZUZA, Júlia Parreira. Mia Couto e Luandino Vieira: a ficção de fronteira nas obras editadas para o público infantojuvenil. 2014. Dissertação (Mestrado) - Faculdade de Letras da Universidade de Coimbra, Coimbra, 2014. Disponível em:

<https://estudogeral.sib.uc.pt/jspui/bitstream/10316/25916/1/dissertacao_Julia_Andrade.pdf>. Acesso em: 4 jun. 2016. 